\title{
GRAIN SIZE DEPENDENT MECHANICAL PROPERTIES IN NANOPHASE MATERIALS*
}

\author{
Richard W. Siegel ${ }^{1}$ and Gretchen E. Fougere ${ }^{2}$ \\ ${ }_{1}$ Materials Science Division, Argonne National Laboratory, Argonne, IL 60439 \\ ${ }^{2}$ Department of Materials Science and Engineering, Northwestern University, \\ Evanston, IL 60208; Present address: Automotive, Energy and Controls Group, \\ Motorola Energy Systems, Northbrook, IL 60062
}

\section{February 1995}

\author{
The submitted manuscript has been authored \\ by a contractor of the U.S. Government \\ under contract No. W-31-109-ENG-38. \\ Accordingly, the U.S. Government retains a \\ nonexclusive, royalty-free license to publish \\ or reproduce the published form of this \\ contribution, or allow others to do so, for \\ U.S. Govemment purposes.
}

\section{DISCLAIMER}

\begin{abstract}
This report was prepared as an account of work sponsored by an agency of the United States Government. Neither the United States Government nor any agency thereof, nor any of their employees, makes any warranty, express or implied, or assumes any legal liability or responsibility for the accuracy, completeness, or usefulness of any information, apparatus, product, or process disclosed, or represents that its use would not infringe privately owned rights. Reference herein to any specific commercial product, process, or service by trade name, trademark, manufacturer, or otherwise does not necessarily constitute or imply its endorsement, recommendation, or favoring by the United States Government or any agency thereof. The views and opinions of authors expressed herein do not necessarily state or reflect those of the United States Government or any agency thereof.
\end{abstract}

INVITED PAPER presented at the Materials Research Society 1994 Fall Meeting, Symposium Jb: "Grain Size and Mechanical Properties," Boston, MA, November 28-December 2, 1994; to be published in the Proceedings "Grain Size and Mechanical Properties-Fundamentals and Applications."

\footnotetext{
*Work supported by the U.S. Department of Energy, Basic Energy Sciences-Materials Sciences, under contract \#W-31-109-ENG-38 at Argonne National Laboratory and Grant DE-FG0286ER45229 at Northwestern University.
} 


\section{DISCLAIMER}

\section{Portions of this document may be illegible in electronic image products. Images are produced from the best available original document.}




\title{
GRAIN SIZE DEPENDENT MECHANICAL PROPERTIES IN NANOPHASE MATERIALS
}

\author{
RICHARD W. SIEGEL* AND GRETCHEN E. FOUGERE**
}

*Materials Science Division, Argonne National Laboratory, Argonne, Illinois 60439 USA **Department of Materials Science and Engineering, Northwestern University, Evanston, Illinois 60208 USA; Present address: Automotive, Energy and Controls Group, Motorola Energy Systems, Northbrook, Illinois 60062 USA

\begin{abstract}
It has become possible in recent years to synthesize metals and ceramics under well controlled conditions with constituent grain structures on a nanometer size scale (below $100 \mathrm{~nm}$ ). These new materials have mechanical properties that are strongly grain-size dependent and often .significantly different than those of their coarser grained counterparts. Nanophase metals tend to become stronger and ceramics are more easily deformed as grain size is reduced. The observed mechanical property changes appear to be related primarily to grain size limitations and the large percentage of atoms in grain boundary environments. A brief overview of our present knowledge about the grain-size dependent mechanical properties of nanophase materials is presented.
\end{abstract}

\section{INTRODUCTION}

The ability to mechanically deform materials depends fundamentally upon the nature of bonding among their constituent atoms and upon their-microstructures on a variety of length scales. Elastic mechanical deformation is effected through reversible changes in the interatomic spacings or the bending. and stretching of bonds between atoms; it is related to the elastic constants or moduli of a material, which indicate how easily such deformation occurs. For metals, such deformation is in general relatively easy owing to the non-local nature of metallic bonding, but for materials with strong covalent or ionic bonding, such as intermetallic compounds or ceramics, it is much more difficult. Plastic deformation, on the other hand, takes place by virtue of a variety of irreversible atomicscale mechanisms, although the ease of these also depend upon the nature of the bonding in similar ways.

In terms of plastic deformation, grain size reduction can yield improvements in strength and hardness (1). At larger grain sizes, this results from the introduction of additional grain boundaries that can act as effective barriers to dislocation motion and at the smallest grain sizes in the nanoscale regime from the paucity of existing dislocations and the difficulty in generating new ones $(2,3)$. Hence, it has been found that grain size reduction, from the conventional tens to hundreds of $\mu \mathrm{m}$ to the nanophase regime below $100 \mathrm{~nm}$, leads to improvements in these mechanical properties. However, grain size reduction may negatively impact other mechanical properties, such as creep rate and ductility. On the other hand, in materials that are conventionally quite strong but very 
brittle, such as intermetallic compounds and ceramics, enhanced ductility from grain size reduction, through the increased probability of grain boundary sliding, can offer considerable processing and performance advantages. Our current understanding of the mechanical properties of nanophase materials is briefly reviewed here. More extensive reviews by the present authors, from which the present paper was derived, appear elsewhere $(4,5)$ and can be consulted for further details and references.

\section{HARDNESS}

The experimental results to date for room temperature microhardness testing of pure nanophase metals show these materials to be considerably harder, by factors from 2 to 7 , than their coarse-grained counterparts. Hardness increases with decreasing grain size $d$ are apparently independent of synthesis method, since nanophase metals produced by gas condensation $(6,7)$, mechanical attrition $(8,9)$, electrodeposition $(10,11)$, and wear $(12)$, and also a nanophase semi-metal formed by crystallization (13) all.show similar trends shown in Fig. 1. On the other hand, several studies have shown that when intermetallic alloy samples.are tested, initial hardening with decreasing grain size is also observed, but that at further reduced grain sizes either hardening at a reduced slope occurs or softening is often seen, as shown in Fig. 2. Nanophase intermetallics produced by gas condensation (14), mechanical attrition (15-17), electrodeposition (18), and crystallization from amorphous precursors (19-23) show that these effects are independent of synthesis method. However, the observed transitional behavior from hardening to softening with decreasing grain.size can be quite complex. Thermal treatments of nanophase alloy samples and grain size variation itself may cause changes in the structure and composition of the grain boundaries, densification, phase transformations, and stress relief, any of which may affect the relationship between grain size and hardness.

While the hardness of pure metals clearly increases as their grain sizes are reduced into the nanophase regime, the full extent of this hardening is not yet clear. Insufficient data exist for a comparison of hardness measurements on the same nanophase material made by different methods. The presence of sample porosity, flaws, or contamination from synthesis and processing could influence the available hardness results, as could the nature of the grain boundaries and their state of relaxation. Nevertheless, the strong similarities among the grain-size dependent hardness data shown in Fig. 1 and also in Fig. 2 indicate that at least the trends appear to be reproducible from method to method among the data for pure metals and for intermetallic alloys.

\section{TENSILE STRENGTH AND FRACTURE}

The nanophase materials tested in tension thus far have been face-centered cubic metals; they have exhibited similar improvements in strength as those seen in their hardness behavior, but they have also showed limited ductility. Relative to their coarsegrained counterparts, the tensile strength of the nanophase metals increased by factors ranging from 1.5 to 8 depending on their grain size and the material (6). The extent to 


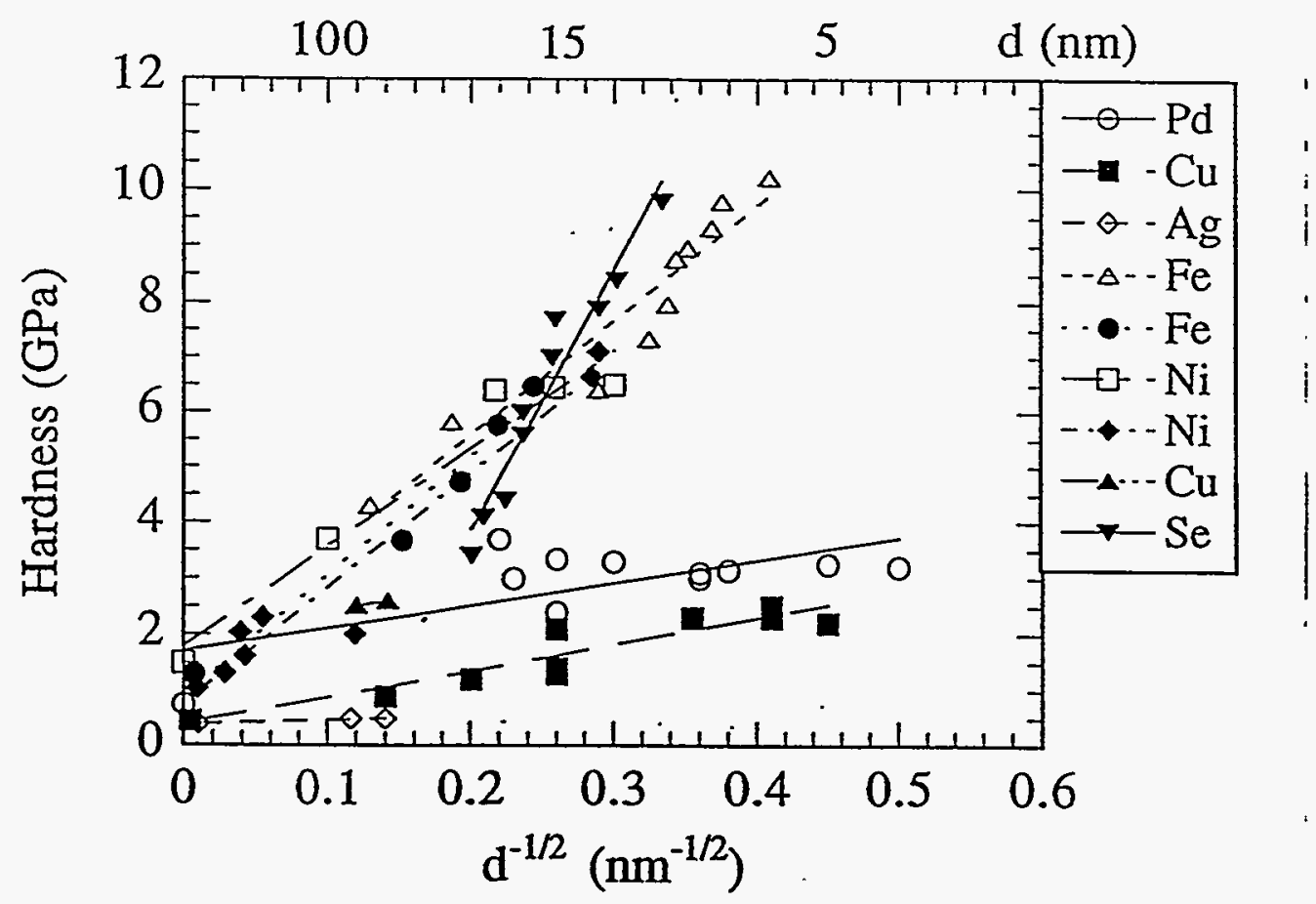

Figure 1. Room temperature hardness versus grain size for nanophase metals (6-13) compared with that of their coarse-grained counterparts (values near origin). From (5).

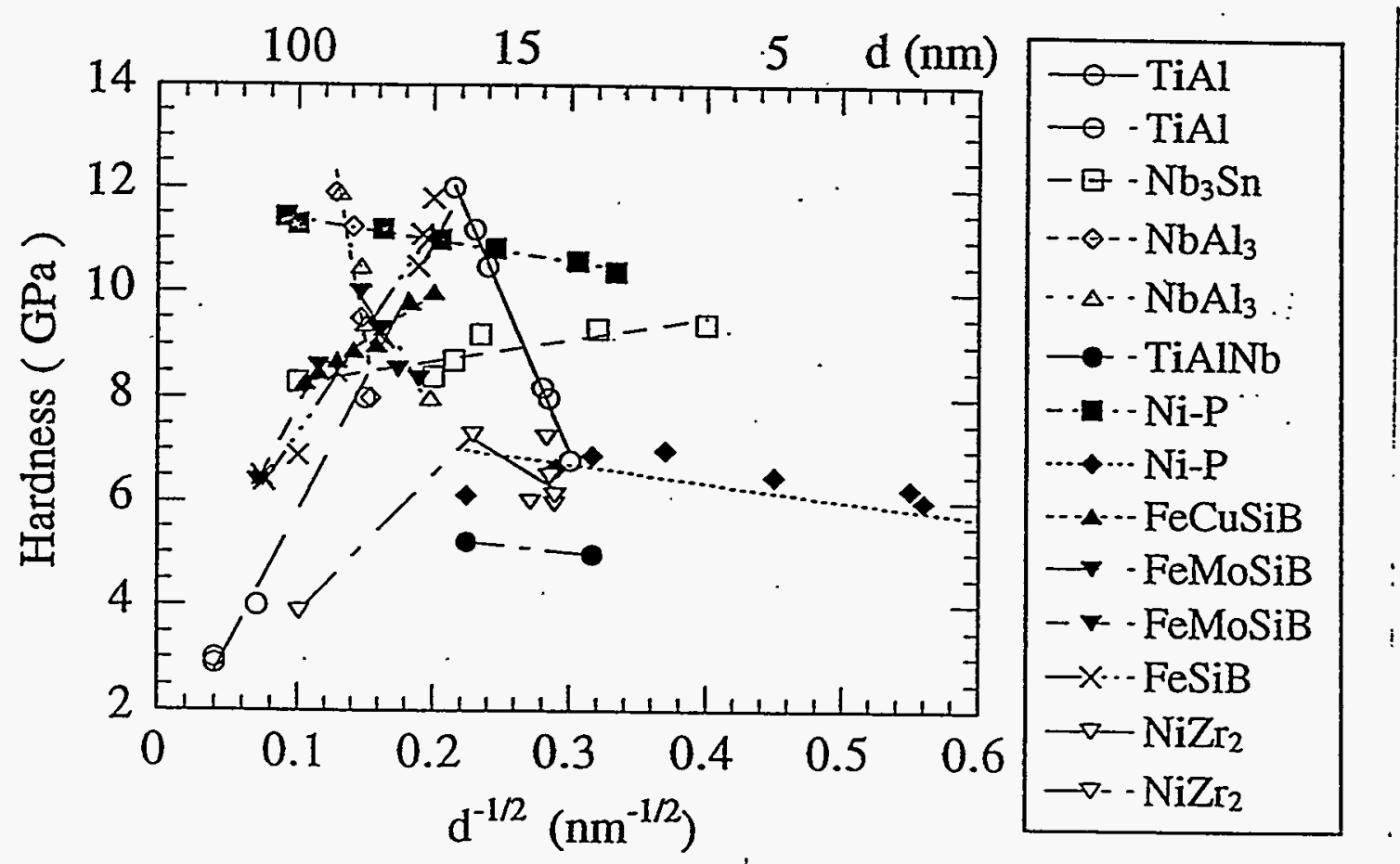

Figure 2. Room temperature hardness versus grain size for a variety of nanophase intermetallic-alloys (14-17,19-23) and a Ni-P solid solution (18). From (5). 
which the tensile strength improved with grain size refinement to about $25 \mathrm{~nm}$, for example, is on the order of that produced by cold working polycrystalline material (7). The limited levels of ductility exhibited by nanophase metals may possibly arise because of difficulties in creating, multiplying, and moving dislocations, but may as well relate to the presence of significant flaw populations in these materials $(6,24)$. Retesting of larger grained $(\mathrm{d}=50 \mathrm{~nm})$ nanophase $\mathrm{Ag}$ did show enhanced ductility and some evidence of work hardening (7). Annealing after consolidation has resulted in improved ductility of cluster consolidated nanophase metals (25) and of mechanically attrited submicron grain-size materials (26).

Elastic modulus changes can occur as materials enter the nanophase regime; however, reduced apparent modulus values can also result from sample porosity. The apparent elastic moduli measured to date on nanophase materials have been decreased in value relative to those in their coarse-grained counterparts, probably because of porosity and flaws resulting from processing (6,27-29). For example, nanophase Fe samples with residual 2-30\% porosities had apparent Young's moduli which were reduced significantly relative to that of conventional Fe because of their pores (29). On the other hand, the Young's modulus of pore-free, electrodeposited nanophase Ni-P (30) was found to be comparable to that for coarse-grained $\mathrm{Ni}$.

The results to date on the fracture properties of nanophase materials have been limited in scope and hindered by the presence of porosity or interfacial phases. in the samples tested. Bending tests of fully-dense Ni-P showed that the grain size reduction into the $\mathrm{nm}$ regime resulted in higher values of the fracture stress and the strain to fracture (31). The variations in the fracture properties due to grain size were attributed to the changes in the volume fraction and density of the interfaces. However, the acknowledged presence of additional phases of free $\mathrm{Ni}$ and $\mathrm{Ni}_{3} \mathrm{P}$.complicates the interface-controlled fracture behavior (32). HREM studies of in-situ fracture of nanophase $\mathrm{Au}$. and $\mathrm{Au} / \mathrm{Si}$ composite films on Al substrates showed a strong dependence of the fracture behavior on the grain size (33). For grain sizes below $25 \mathrm{~nm}$ and slow strain rates, the deformation and fracture were driven by diffusional mechanisms bridging the crack formation and propagation. When the grain size was increased above $35 \mathrm{~nm}$, the cracks grew both through and around the grains. In both grain size regions, the contribution to plasticity by dislocations was deemed negligible because dislocations were not imaged during the testing. However, delocalized dislocation structures that would yield weak TEM images cannot be ruled out as possible contributors to material flow in these experiments.

A qualitative study (34) of the fracture surfaces of sintered nanophase $\mathrm{TiO}_{2}(\mathrm{~d}=12$ $\mathrm{nm}$ ) was done to compare these surfaces with those of sintered coarser-grained $\mathrm{TiO}_{2}$ $(d=1.3 \mu \mathrm{m})$. The lower microhardness and comparable fracture toughness of the coarsegrained material was attributed to the larger and greater number of voids in these samples. A fracture toughness increase in this material of a factor of 2 has also been reported (35). Predictions of enhanced ductility and fracture toughness also have been offered for nanophase WC-10\% Co with $200 \mathrm{~nm}$ grain size; the predictions were based on observed hardness increases with grain size refinement (36).

Quantitative estimates of the fracture toughness based on the lengths of cracks emanating from microhardness indentations have been made for nanophase $\mathrm{TiO}_{2}$ (37). As the grain size of about $10 \mathrm{~nm}$ was increased by annealing up to $800^{\circ} \mathrm{C}$; the fracture toughness increased by a factor of 3.5 and the hardness increased to the range of well- 
sintered coarse-grained $\mathrm{TiO}_{2}$. As a result of the sintering, the porosity decreased from $25 \%$ to $10 \%$ and the grain size increased to about $100 \mathrm{~nm}$; therefore, the contributions of the porosity and of grain size to the mechanical properties could not be separated as they changed concurrently. Subsequent studies of fully-dense $\mathrm{TiO}_{2}$ indicated that the fracture toughness is independent of the grain size when the grain size is less than $500 \mathrm{~nm}$ and is typical of single crystal $\mathrm{TiO}_{2}(38)$.

\section{COMPRESSIVE STRENGTH AND CREEP}

Nanophase forms of conventionally brittle intermetallics and ceramics have demonstrated greatly enhanced ductility (39-41). For example, it was recently shown (41) that after the mechanical attrition of $75 \mu \mathrm{m}$ grain size $\mathrm{Fe}-28 \mathrm{Al}-2 \mathrm{Cr}$ powder to produce 80 $\mathrm{nm}$ grain size nanophase material, and subsequent shock consolidation, the samples, when tested in compression at room temperature, exhibited extreme plasticity (true strains $>1.4$ ) and increased yield strength (almost 10 times that of the coarse-grained material), as well as a further average grain size reduction to ca. 10-15 $\mathrm{nm}$.

Hardness tests at elevated.temperatures can also indicate compressive creep behavior of nanophase materials. Although typically used as a static tool, by increasing the loading times with a constant load and at temperature, the indentation size can be monitored to yield dynamic compressive behavior. In such a way, the indentation sizes on nanophase TiAl with ca. $10 \mathrm{~nm}$ average grain size were seen to increase rapidly and then more slowly, indicating that a diffusion-controlled deformation process was occurring (42). The data obtained appear to follow the Ashby-Verrall creep model (43) with a threshold stress occurring for a load $>100 \mathrm{~g}$. At low temperatures, the nanophase TiAl (14).showed little change in hardness until the temperature rose to the point that thermally activated deformation by diffusional creep started. An observed drop in hardness with temperature was attributed partially to densification under the indentation load and primarily to enhanced flow of the material (42).

To date, the sole creep measurements on nanophase metals have been made in tension on $\mathrm{Cu}$ and $\mathrm{Pd}(6)$ at room temperature; these exhibited. stress-strain behavior logarithmic with time that apparently. resulted from dislocation activity (44). No evidence for significantly enhanced Coble creep, as suggested by some earlier measurements on nanophase metals (45) and ceramics (46), was observed at room temperature for either $\mathrm{Cu}$ or Pd.

The first published indications of plasticity of nanophase ceramics at low temperatures were the hardness results for nanophase $\mathrm{CaF}_{2}$ and $\mathrm{TiO}_{2}$ (46) The single crystal analogs of these materials failed in a brittle mode; however; the nanophase samples showed plastic deformations of about $100 \%$ when tested at moderate temperatures compared to their single crystal and polycrystalline coarse-grained analogs. These results suggested that nanophase ceramics would exhibit enhanced ductility at lower temperatures than those required for coarse-grained ceramics to behave superplastically. True compressive creep testing of nanophase ceramics has substantiated this enhanced plasticity. Compressive creep tests (47) conducted at moderate temperatures on $99 \%$ dense nanophase $\mathrm{TiO}_{2}$ showed extensive deformation without crack formation. 
Nanoindentation experiments on nanophase $\mathrm{TiO}_{2}(48)$ and $\mathrm{ZnO}$ (49) at room temperature yielded the first quantitative results for the strain rate sensitivity, $\mathrm{m}$, of nanophase materials. The values of $\mathrm{m}$ showed an almost exponential increase with decreasing grain size in the range of $d$ from about 30 to $7 \mathrm{~nm}$, as shown in Fig. 3. The $m$ values were increased relative to those of coarse-grained ceramics, yet the maximum value ( $m=0.04)$ measured at room temperature was still an order of magnitude below that normally representative of superplasticity (ca. 0.3 ). The strain rate sensitivity of 70 and $50 \mathrm{~nm}$ grain size $\mathrm{Cu}$ was 3 to 5 times that of $50 \mu \mathrm{m}$ grain size $\mathrm{Cu}$, as measured by nanoindentation (12).

The stress exponent $n$ (the reciprocal of $m$ ) has also been measured in the compressive testing of nanophase ceramics as a method of determining their creep deformation processes. For partially-stabilized zirconia, $\mathrm{ZrO}_{2}-3 \mathrm{~mol} \% \mathrm{Y}_{2} \mathrm{O}_{3}$, the measured stress exponent was $3(50,51)$; the second phase of $\mathrm{Y}_{2} \mathrm{O}_{3}$ added in small quantities can be useful in stabilizing the host material $\mathrm{ZrO}_{2}$ against grain growth. Similar values of $\mathrm{n}$ were measured for nanophase $\mathrm{TiO}_{2}(47,52)$ and $\mathrm{ZrO}_{2}(53)$; later tests of nanophase $\mathrm{TiO}_{2}$ demonstrated $n$ values between 2.2 and $2.6(54)$, very close to the limits of superplasticity. Compressive tests of a nanophase $\mathrm{TiO}_{2}-\mathrm{Y}_{2} \mathrm{O}_{3}$ solution (55) showed $\mathrm{n}>5$. All of these values indicate interface-controlled creep:

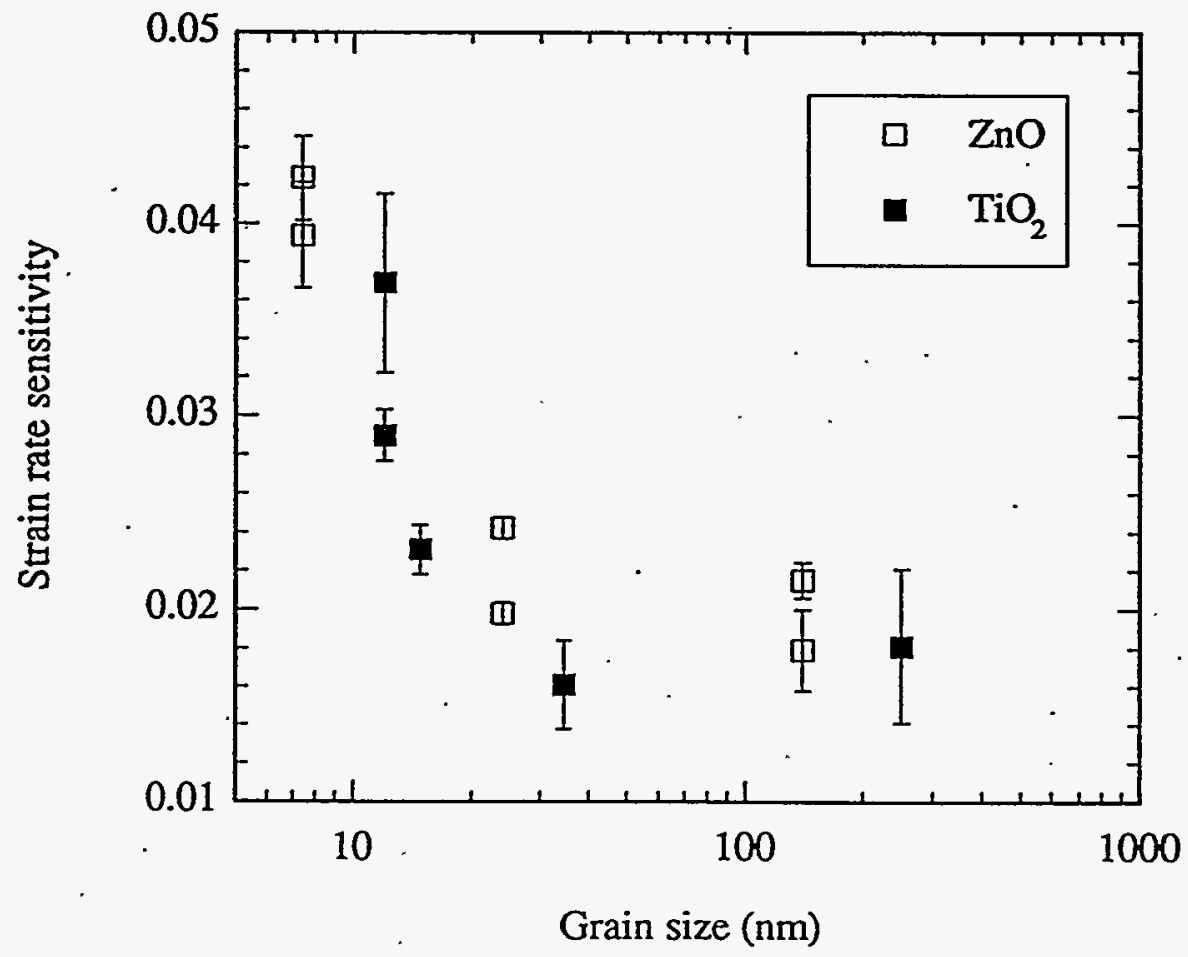

Figure 3. Strain rate sensitivity of nanophase $\mathrm{TiO}_{2}(48)$ and $\mathrm{ZnO}(49)$ as a function of grain size. The strain rate sensitivity was measured by nanoindentation and the grain size was determined by dark-field transmission electron microscopy. 
Another indication of the creep mechanisms operating in nanophse ceramics is the dependence of the strain rate on the grain size. The grain size dependence, $p$, of the strain rate was measured in nanophase $\mathrm{ZrO}_{2}-3 \mathrm{~mol} \% \mathrm{Y}_{2} \mathrm{O}_{3}$ to be 2.66 when the original grain size was used or 4 when the instantaneous grain size was used (39). The value of $p$ for two studies of nanophase $\mathrm{TiO}_{2}$ was 1.7 in (54) and varied between 1.0 and 1.5 in (55). However, this parameter may be less meaningful in the quest to determine the phenomena driving creep because the grain size can change dramatically during the course of a high temperature experiment and these changes can be highly dependent in turn on porosity.

Nanophase $\mathrm{TiO}_{2}$ has been formed to a desired shape with excellent detail below $900^{\circ} \mathrm{C}(35)$. A test of the formability typically performed on sheet metals, the biaxial bulge test, can also be utilized to evaluate the ductility of nanophase materials; it is more severe than the typical uniaxial tensile test, since flaws of all orientations can be stressed to cause fracture. Cui and $\mathrm{Hahn}(56)$ have subjected nanophase $\mathrm{TiO}_{2}$ of $40 \mathrm{~nm}$ grain size to bulge tests at temperatures between 700 and $800^{\circ} \mathrm{C}$ and found ductile behavior. The samples deformed up to true strain levels of 0.1 without the formation of any cracks. These results confirm that the plasticity seen in compressive creep testing also occurs during tensile testing and could be used to form these materials. Young's modulus values measured on nanophase oxide ceramics have indicated that compression measurements were influenced by the effects of porosity, as was the case for the tensile measurements of metals. Nanoindentation experiments on nanophase $\mathrm{TiO}_{2}$ (48) (initially $75 \%$ dense) and $\mathrm{ZnO}$ (49) (initially $85 \%$ dense) yielded values of the Young's modulus, based on the slope of the unloading portion of the indentation curve, between 60 to $80 \%$ of that of their fully dense coarse-grained analogs.

\section{DISCUSSION AND CONCLUSIONS}

The available body of data on the mechanical properties of nanophase materials, while still rather limited, has now grown to the point where a certain consistency is emerging and some general conclusions can be drawn (5).

It seems apparent from the generally observed increase in hardness with decreasing grain size, as well as from the observations. of work hardening, decreased ductility, and logarithmic creep, that.dislocation activity still dominates the mechanical behavior of pure nanophase metals over the grain sizes that have been investigated. However, the dislocation activity appears to continually decrease with decreasing grain size from those levels normally found in conventional pure metals owing to a combination of the decreased availability of dislocations and the decreased ability to create new dislocations in the increasingly confined nanophase grains. Conventional Hall-Petch hardening from the introduction of increasing numbers of grain boundaries as barriers against dislocation motion seems to play an insignificant role in this grain size regime. The paucity of mobile dislocations in nanophase grains has been well documented experimentally (57) and is simply a result of the well understood image forces that act on dislocations near surfaces and hence in confined media (58). The difficulty in creating new dislocations within the spatial confinements of ultrafine crystallites has also long been evident from earlier research on single crystal whiskers and wear debris $(2,3)$. Since the minimum stresses required to activate common dislocation sources (such as a Frank-Read source) are inversely 
proportional to the distance between dislocation pinning points, these stresses will increase dramatically with decreasing grain sizes into the nanophase regime owing to the limitation of the maximum distance between such pinning points. As metal grain sizes shrink down to ca. 1-2 nm (the actual number depends upon the specific value of the shear modulus), the theoretical yield stress of a dislocation free metal may be approached. Thus, it appears that the increasing hardness and strength observed in pure nanophase metals with decreasing grain size is simply a result of diminishing dislocation activity. While other mechanisms that have been recently suggested (59-63) may also play a role, no substantial experimental evidence for metal softening in this regime has yet been produced.

The situation regarding the observed mechanical behavior of nanophase intermetallic alloys or compounds is more complex, but also appears to have some degree of consistency. This is the case even though significant questions can and should be raised regarding the various effects of the grain size dependence of phase stability and solute segregation in the nanophase regime in these materials and even regarding the definition of grain sizes in these frequently multiphase systems. Nevertheless, for a number of the nanophase intermetallics investigated thus far, the mechanical response in the larger end of the nanophase grain size regime seems rather similar to that for the pure metals. However, a number of these typically harder.and more strongly bound materials exhibit a clear transition from hardening behavior to softening behavior with decreasing grain sizes or, in some cases, only softening. The softening behavior or increased ductility appears to be related to an increase in grain boundary sliding with decreasing grain size as evidenced by stress-strain and creep measurements, although direct metallographic observations of grain boundary sliding are still lacking in these materials. The mechanical response of these intermetallics thus appears to be transitional between that of pure nanophase metals at larger grain sizes and approaching at smaller grain sizes that observed for nanophase ceramics. Thus, grain boundary sliding mechanisms, accompanied by short-range diffusion assisted healing events, appear to increasingly dominate the deformation behavior of strongly bound and conventionally brittle materials in their nanophase forms. This deformation by grain boundary sliding also appears to have its analogue in the cluster consolidation process for creating nanophase materials in which the typically equiaxed clusters formed by gas condensation retain both their general morphologies and random orientations during consolidation by means of diffusional events akin to Ashby-Verrall creep:

The mechanical behavior of nanophase materials reviewed in this paper suggests that a qualitative framework (5), shown in Fig. 4, for understanding the mechanical properties of nanophase materials in general may be useful to consider. It appears that with decreasing grain size into the nanophase regime, the frequency of dislocation-activity decreases and that of grain boundary sliding increases. Which of these effects dominates depends upon the grain size regime, the specific type of material, and most importantly on the nature of its interatomic bonding. Thus, metals (e.g., Al) with essentially free-electron-like, nondirectional bonding would fall at the left of Fig. 4 and those with more covalent bonding (e.g., $\mathrm{Cr}$ ) would lie further toward the covalently bonded intermetallic alloys or compounds, which themselves lie in the transitional region where diminishing dislocation activity yields to increasing grain boundary sliding; nanophase ceramics with their strong ionic or covalent bonding would lie in the region to the right dominated by grain boundary sliding.

Much work, of course, remains to fully elucidate the mechanisms responsible for the mechanical behavior of nanophase materials and to test whether such a simple framework as 
this, first proposed in (5), is truly applicable. Critical experiments will need to be performed on a wide variety of nanophase materials with different bonding characteristics to identify the actual atomic mechanisms responsible for their observed mechanical properties and how these fit within the scheme shown in Fig. 4, or whether a new framework will need to be introduced. Nevertheless, the remarkably different mechanical behavior already observed for nanophase materials compared with conventional grain size materials, and the already demonstrated possibilities to engineer this mechanical behavior through grain size control in the nanophase regime, indicate that such research endeavors will yield important results.

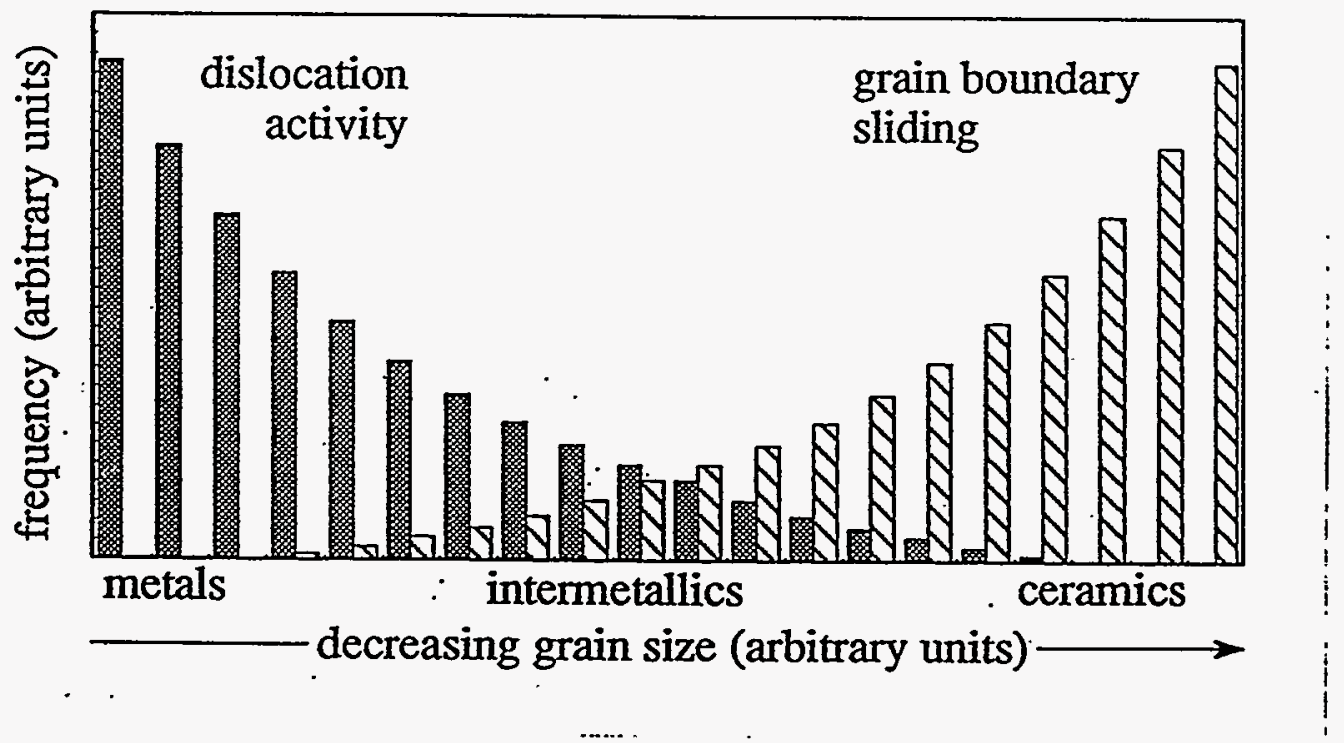

Figure 4. Schematic framework for the grain size dependence of dislocation activity and grain boundary sliding contributions to the deformation behavior of the various classes of nanophase materials (5). The nature of its interatomic bonding determines the appropriate location for a particular material.

\section{ACKNOWLEDGEMENTS}

This work was supported by the U.S. Department of-Energy, Basic Energy SciencesMaterials Sciences under Contract W-31-109-Eng-38 at Argonne National Laboratory and Grant DE-FG02-86ER45229 at Northwestern University.

\section{REFERENCES}

1. M. Nastasi, D. M. Parkin, and H. Gleiter, eds., Mechanical Properties and Deformation Behavior of Materials Having Ultra-Fine Microstructures, (Kluwer, Dordrecht, 1993).

2. L. S. Darken, Trans. Am. Soc. Met. 54, 599 (1961).

3. D. A. Rigney, L. H. Chen, M. G. S. Naylor, A. R. Rosenfield, Wear 100, 195 (1984). 
4. R. W. Siegel and G. E. Fougere, in Nanophase Materials: Synthesis-PropertiesApplications, G. C. Hadjipanayis and R. W. Siegel, eds. (Kluwer, Dordrecht, 1994) p. 233.

5. R. W. Siegel and G. E. Fougere, Nanostruct. Mater. 6, in press (1995).

6. G. W. Nieman, J. R. Weertman, and R. W. Siegel, Scripta Metall. 23, 2013 (1989);

G. W. Nieman, J. R. Weertman, and R. W. Siegel, J. Mater. Res. 6, 1012 (1991);

G. W. Nieman, Ph.D. Thesis, Northwestern University (1991).

7. G. W. Nieman, J. R. Weertman, and R. W. Siegel, in Microcomposites and Nanophase Materials, D. C. Van Aken et al., eds. (TMS, Warrendale, 1991) p. 15.

8. J. S. C. Jang and C. C. Koch, Scripta Metall. et Mater. 24, 1599 (1990).

9. P. Le Brun, E. Gaffet, L. Froyen and L. Delaey, Scripta Metall. et Mater. 26, 1743 (1992).

10. A. M. El-Sherik, U. Erb, G. Palumbo, and K. T. Aust, Scripta Metall. et Mater. 27, 1185 (1992).

11. G. D. Hughes, S. D. Smith, C. S. Pande, H. R. Johnson, and R. W. Armstrong, Scripta Metall. 20, 93 (1986).

12. S. K. Ganapathi, M. Aindow, H. L. Fraser, and D. A. Rigney, Mater. Res. Soc. Symp. Proc. 206, 593 (1991).

13. H. Y. Zhang, Z. Q. Hu, and K. Lu, to be published.

14. H. Chang, C. J. Altstetter, and R. S. Averback, J. Mater. Res. 7, 2962 (1992).

15. C. C. Koch and Y. S. Cho, Nanostruct. Mater. 1, 207 (1992).

16. K. Kim and K. Okasaki, Mater. Sci. Forum 88-90, 553 (1992).

17. T. Christman and M. Jain, Scripta Metall. et Mater. 25, 767 (1991).

18. G. Palumbo, U. Erb, and K. T. Aust, Scripta Metall. et Mater. 24, 2347 (1990).

19. K. Lu, W. D. Wei, and J. T. Wang, Scripta Metall. et Mater. 24, 2319 (1990).

20. X. D. Liu, B. Z. Ding, Z. Q. Hu, K. Lu, and Y. Z. Wang, Physica B 192, 345 (1993).

21. .X. D. Liu, J. T. Wang, and B. Z. Ding, Scripta Metall. et Mater. 28, 59 (1993).

22. H. Y. Tong, J. T. Wang, B. Z. Ding, H. G. Jiang, and K. Lu, J. Non-cryst. Solids 150, 444 (1992).

23. K. Lu et al., to be published.

24. A. Kumpmann, B. Günther, and H.-D. Kunze, in Ref. (1) p. 312.

25. B. Günther, A. Baalman, and H. Weiss, Mater. Res. Soc. Symp Proc. 195, 611 (1990).

26. R. Z. Valiev, N. A. Krasilnikov, and N. K. Tsenev, Mater. Sci. Eng. A 137, 35 (1991).

27. G. W. Nieman, J. R. Weertman, and R. W. Siegel, Scripta Metall. et Mater. 24, 145 (1990).

28. H. Gleiter, Prog. Mater. Sci. 33, 223 (1989).

29. G. E. Fougere, L. Riester, M. Ferber, J. R. Weertman, and R. W. Siegel, Mater. Sci. Eng. A, in press (1995)

30. A. M. El-Sherik, U. Erb, V. Krstic, B. Szpunar, M. J. Aus, G. Palumbo, and K. T. Aust, Mater. Res. Soc. Symp Proc. 286, 173 (1993).

31. M. L. Sui, S. Patu, and Y. Z. He, Scripta Metall. et Mater. 25, 1537 (1991).

32. M. T. Laugier, J. Mater. Sci. Lett. 6, 841 (1987).

33. W. W. Milligan, S. A. Hackney, M. Ke, and E. C. Aifantis, Nanostruct. Mater. 2, 267 (1993). 
34. Z. Li, S. Ramasamy, H. Hahn, and R. W. Siegel, Mater. Lett. 6, 195 (1988).

35. J. Karch and R. Birringer, Ceramics International 16, 291 (1990).

36. L. E. McLandish, B. H. Kear, and B. K. Kim, Nanostruct. Mater. 1, 119 (1992).

37. R. S. Averback, H. Hahn, H. J. Höfler, J. L. Logas, and T. C. Chen, Mater. Res. Soc. Symp. Proc. 153, 3 (1989).

38. H. J . Höfler and R. S. Averback, Scripta Metall. et Mater. 24, 2401 (1990).

39. M. J. Mayo, in Ref. (1) p. 366.

40. H. Hahn, Nanostruct. Mater. 6, in press (1995).

41. M. Jain and T. Christman, Acta Metall. et Mater. 42, 1901 (1994).

42. C. J. Altstetter, in Ref. (1) p. 381.

43. M. F. Ashby and R. A. Verrall, Acta Metall. 21, 149 (1973).

44. J. Weertman and J. R. Weertman, in Physical Metallurgy (2nd Ed.), R. W. Cahn, ed. (North-Holland, Amsterdam, 1970) p. 989.

45. A. H. Chokshi, A. Rosen, J. Karch, and H. Gleiter, Scripta Metall. 23, 1679 (1989).

46. J. Karch, R. Birringer, and H. Gleiter, Nature 330, 556 (1987).

47. H. Hahn, J. C. Logas, H. J. Höfler, and R. S. Averback, Mater. Res. Soc. Symp Proc. 206, 569 (1991).

-48. M. Mayo, R. W. Siegel, A. Narayanasamy, and W. D. Nix, J. Mater. Res. 5,1073 (1990).

49. M. J. Mayo, R. W. Siegel, Y. X. Liao, and.W. D. Nix, J. Mater. Res. 7, 973 (1992).

50. M. Ciftcioglu and M. J. Mayo, Mater. Res. Soc. Symp. Proc. 196, 77 (1990).

51. . M. J . Mayo, in Superplasticity in Advanced Materials, S. Hori et al., eds. (Japan Society for Research on Superplasticity, Osaka, 1991) p. 541.

52. H. Hahn and R. S. Averback, J. Amer. Cer. Soc. 74, 2918 (1991).

53. R. Raj, J. Amer. Cer. Soc. 71, C-507 (1988).

54. H.-J. Höfler and R. S. Averback, Mater. Res. Soc. Symp. Proc. 286, 9 (1993).

55. H. Hahn and R. S. Averback, Nanostruct. Mater: 1, 95 (1992).

56. Z. Cui and H. Hahn, Nanostruct. Mater. 1, 419 (1992).

57. R. W. Siegel, in Encyl. of Appl. Physics, Vol. 11, G.L. Trigg, ed. (VCH, Weinheim, 1994) p. 173.

58. A. E. Romanov, Nanostruct. Mater. 6, in press (1995).

59. T. G. Nieh and J. Wadsworth, Scripta Metall. et Mater. 25, 955 (1991).

60. R. O. Scattergood and C. C. Koch, Scripta Metall. et Mater. 27, 1195 (1992).

61. K. Lu and M. L. Sui, Scripta Metall. et Mater. 28, 1465 (1993).

62. J. Lian and B. Baudelet, Nanostruct. Mater. 2, 415 (1993).

63. V. G. Gryaznov and L. I. Trusov, Prog. Mater. Sci. 37, 289 (1993). 